\title{
Metafilosofía jurídica de los siglos XX y XXI: ¿un concepto analítico de derecho?
}

NicolÁs LóPEZ

Universidad de Chile

Resumen: Este trabajo pretende hacer una reconstrucción metafilosófica del derecho en la tradición analítica, puntualmente entre el siglo $X X$ y los tres primeros lustros del $X X I$, con el objeto de determinar la identidad del concepto analítico de derecho. Para dicho fin, se dispondrá de tres ejes argumentativos. El primero dilucidará la distinción entre los enfoques continental y anglosajón de la filosofía jurídica analítica del siglo $X X$. El segundo eje se centrará en los métodos y propósitos de esta última, desde el período posterior a la publicación de la primera edición de The Concept of Law de Hart (196I) hasta su segunda edición en 1994. El tercero problematizará la existencia o inexistencia de un concepto analítico del derecho.

Palabras clave: metafilosofía, The Concept of Law, metodología, análisis conceptual, tradición analítica.

\begin{abstract}
This paper aims to offer a metaphilosophical reconstruction of Law in the analytic tradition of the twentieth and twentieth-one century first fifteen years, in order to determine the identity of the "analytic concept of law". To do that I will use three argumentative axes. The first will clarify the distinction between the Continental and Anglo-Saxon focuses on twentieth century analytical legal philosophy. The second axis will emphasize the methods and purposes of the latter, from the publication of Hart's The Concept of Law's first edition to its second edition in 1994. The third will problematize the existence or non-existence of an analytical concept of Law.
\end{abstract}

Keywords: Meta-philosophy, The Concept of Law, Methodology, Conceptual Analysis, Analytic Tradition. 
Nada es más importante que la formación de los conceptos de ficción, los que nos enseñan por fin a comprendernos a nosotros mismos'.

Ludwig Wittgenstein

Es una tarea de la filosofía romper el dominio de la palabra sobre la mente humana al descubrir los engaños que sobre las relaciones de los conceptos surgen casi inevitablemente en el uso del lenguaje ${ }^{2}$.

Gottlob Frege

\section{§ 1. Introducción}

Desde la publicación de The Concept of Law (196I) de H.L.A. Hart, la reflexión teórica en el derecho ha tenido un exponencial aumento. El filósofo y abogado británico sugiere prestar atención a las sutilezas de nuestras formas de hablar $y$, como lo jurídico se funda en la comprensión de los conceptos usados cotidianamente, esto implicaría "no dar un concepto (unívoco) de derecho" ${ }^{3} \mathrm{y}$, al mismo tiempo, otorgar herramientas para el estudio de ellos. El fenómeno jurídico, para Hart, se construye a partir de usos y prácticas lingüísticas. Esta aproximación valorativa resulta inédita, ya que el estado del arte se reduce a tesis monistas donde el derecho, en su continuidad, se asemeja a una ciencia predictiva.

En el espectro filosófico del derecho hay una multiplicidad de respuestas a la inquietud ontológica de lo jurídico y la coexistencia de diferentes teorías y enfoques sobre el derecho es, quizás, lo que permite avanzar a los estudios en la materia. Una de estas teorías es la que surge con el giro lingüístico, o sea, con la concepción de que los problemas metafísicos y epistemológicos del mundo son, en realidad, problemas sobre el lenguaje ${ }^{4}$. La filosofía analítica bien aprovechó esta nueva concepción de los asuntos filosóficos que se consolidó

I Wittgenstein, Ludwig, Culture and Value, Oxford: Blackwell, 1980, p. 85e. Traducción propia.

2 Frege, Gottlob, Conceptografía. Los fundamentos de la aritmética, México D.F.: UNAM, 1972, p. 5.

3 Hart, H.L.A., The Concept of Law, 2da. edición, Oxford: Clarendon Press, 1994, capítulo VIII, pp. I55-I84.

4 Cf. Rorty, Richard, El giro lingüístico, traducción de Gabriel Bello, Barcelona: Paidós, 1998, pp. 5I-I26. 
en el siglo XX como una tradición de pensamiento, extendiéndose a todas las ramas de la filosofía, tanto puras como aplicadas. Ahora bien, una tradición filosófica, según M.E. Orellana Benado, se compone de tres dimensiones: una conceptual (problemas, intuiciones, interrogantes, argumentos y objeciones), una institucional (universidades, libros, seminarios, simposios donde se expresa lo conceptual, proyectos de investigación, artículos en revistas académicas, centros de estudios) y una política (relaciones de poder que se suscitan entre las distintas concepciones intra-tradicional o inter-tradiciones que se pueden materializar como alianzas y rivalidades) $)^{5}$. Por ello, para acercarse a la idea de una tradición analítica, es necesario identificar sus dimensiones como conformando una familia. Es requisito sine qua non de una tradición tener más de una visión acerca de la filosofía y, por tanto, más de una manera de producirla. Esto último tiene relación con el problema del método (y se amplía hasta el objeto de estudio): como no hay uniformidad de método, entonces, en palabras de Michael Dummett, "la manera de responder a las inquietudes

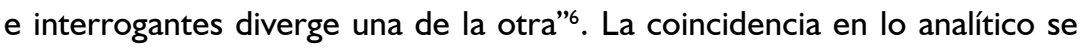
constriñe a otros parámetros ${ }^{7}$.

En el siglo $X X$, además de la tradición analítica, se ubican la existencialista, la marxista y la tomista. Este trabajo profundizará solo en la primera, con especial énfasis en su faceta iusfilosófica, indagando entre dos distinciones principales: una conceptual y la otra sistémica. Respecto a lo conceptual, se presentarán dos tipos de productos filosóficos: cientificismo y cotidianismo. Esto se manifiesta en el estudio de tres textos importantes del siglo XX: la Reine Rechtslehre (Teoría pura del derecho, 1934 y 1960) de Hans Kelsen, Om Ret og Retfærdighed (Sobre el derecho y la justicia, 1953) de Alf Ross y The Concept of Law (El Concepto de Derecho, 196I) de H.L.A. Hart.

Este trabajo pretende hacer una reconstrucción metafilosófica del derecho en la tradición analítica, puntualmente entre el siglo $X X$ y los tres primeros lustros del XXI. Se entenderá por metafilosofía al "conjunto de estudios dedicados

5 Cf. Orellana Benado, M.E., “Tradiciones y concepciones en filosofía”, en: Nudler, Óscar (ed.), Filosofía de la filosofía. Enciclopedia iberoamericana de filosofía, vol. 31, Madrid: Trotta, 2010, p. 54.

6 Dummett, Michael, Origins of Analytic Philosophy, Londres: Duckworth, 1993, p. 5.

7 Cf. Biletski, Anat y Anat Matar (eds.), The Story of Analytic Philosophy: Plot and Heroes, 
al análisis y métodos de la actividad filosófica en los cuales se engloban los trabajos que atienden al lenguaje filosófico, a la estructura o historia de la filosofía, así como todos aquellos que consideran que la filosofía ha desapare-

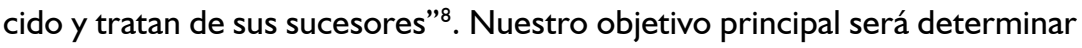
la identidad del concepto analítico de derecho y, para ello, dispondremos de tres ejes argumentativos. El primero dilucidará la distinción entre los enfoques continental y anglosajón de la filosofía jurídica analítica del siglo XX. EI segundo eje se centrará en los métodos y propósitos de esta última desde el período posterior a la publicación de la primera edición del trabajo de Hart hasta su segunda edición en 1994. El tercero problematizará la existencia o inexistencia de un concepto analítico del derecho.

\section{§ 2. La filosofía analítica del derecho del siglo $X X$}

\subsection{Dos caras continentales}

La presentación de un entendimiento del derecho en la filosofía analítica parte con los trabajos de Hans Kelsen, Alf Ross y H.L.A. Hart. Esta intuición considera las distintas concepciones que se agrupan en esta forma de hacer filosofía, particularmente, sobre la distinción entre una vertiente cientificista y una cotidianista en la tradición analítica de la filosofía. La visión cientificista del mundo es un concepto histórico ramificado en la modernidad y se proyectó por más de 400 años bajo la égida del empirismo británico, el positivismo comteano, el logicismo fregeano y una comprensión "perfecta" de la concepción del mundo extendida en gran medida por el Círculo de Viena durante el siglo XX.

La concepción cientificista se caracteriza por afirmar que la filosofía es continua con la ciencia y, en base a ello, busca el establecimiento de un lenguaje lógico que sea ideal para responder todas las preguntas que surjan en la naturaleza y cuya veracidad sea susceptible de ser comprobada mediante la experimentación o la verificación de las hipótesis de investigación. Naturalmente, las concepciones filosóficas primero proliferan en torno a las ramas de la filosofía pura, a saber, la metafísica, la epistemología, la lógica y la ética

8 Ferrater Mora, José, Diccionario de filosofía, 6ta. edición, Barcelona: Ariel, 1979, pp. 2377-2378. 
(acompañada de la estética). En lo que concierne a la filosofía jurídica, una de las ramas aplicadas de la disciplina, la concepción cientificista está mejor representada en la Reine Rechtslehre de Kelsen, cuya primera publicación fue en 1934. Sus manifestaciones teóricas, en primer lugar, recaen en el interés por definir al derecho como un sistema entre cuyos elementos (las normas jurídicas) se dan relaciones de derivación similares a las que se encuentran en la lógica9. Kelsen presenta una comprensión de la norma jurídica a partir del criterio de la validez jurídica; en sus palabras: "una norma jurídica es válida si deriva de otra superior, en el sentido de que ha sido concebida de acuerdo a los procedimientos establecidos por la norma de mayor jerarquía"|0.

La tesis de Kelsen es reduccionista, pues entiende que es posible diferenciar la estructura elemental que subyace a todas las normas jurídicas por medio de un análisis que recuerda a los de Russell en On Denoting (1905)". El jurista concluye que la estructura de todas las normas jurídicas es una instrucción que faculta a un oficial (juez) para aplicar una sanción a quien satisfaga la condición prevista en la norma, o sea, la conducta prohibida. La tipología de las reglas en la Reine Rechtslehre se resume en enunciados que describen un supuesto de hecho que, de darse, estatuye una sanción. Entonces, la definición de las normas se da en un sentido negativo'2, bajo el algoritmo: "Si A es $B$, debe ser C", donde $A$ es la conducta del sujeto, $B$ el supuesto de hecho que establece un determinado escenario en el mundo que, si es cumplido por el sujeto $A$, cabe C (la sanción), o sea, el efecto de este proceso, llamado de subsunción lógica'3.

En el enfoque continental de la filosofía jurídica analítica, cercano al texto de Kelsen, se encuentra la tesis sobre el derecho de Ross, representante de otra concepción cientificista en la tradición analítica de la filosofía jurídica. A diferencia de la Reine Rechtslehre, cuyo interés se limita a los aspectos formales del derecho, Ross sostiene una aproximación al derecho como un fenómeno

9 Cf. Luhmann, Niklas, Rechtssoziologie, Opladen: Westdeutscher, 1987, pp. 226-26I.

10 Kelsen, Hans, Teoría pura del derecho, traducción de Roberto Vernengo, 2da. edición, México D.F.: UNAM, 1982, pp. 123-129.

II Cf. Russell, Bertrand, "Sobre el denotar", en: Moro Simpson, Thomas (comp.), Semántica filosófica: problemas y discusiones, Buenos Aires: Siglo XXI, 1973, pp. 29-48.

I2 Cf. Kelsen, Hans, op. cit., p. 47.

13 Véase Alchourrón, Carlos y Eugenio Bulygin, Análisis lógico y Derecho, Madrid: Centro de 
puramente empírico basada en el concepto del "derecho vigente"|' . Según este, la validez jurídica se reduce a la conjunción entre la efectividad social y el sentimiento, por parte de los sujetos sometidos al derecho, de que sus normas son obligatorias.

Como se ha dicho anteriormente, Kelsen y Ross manifiestan tesis que se acoplan a la concepción cientificista de la tradición analítica de la filosofía jurídica. En una genealogía de la tradición analítica del siglo $X X$, se exhibe un predominio de la concepción cientificista hasta la 1950. Ese año, la crítica de P.F. Strawson en contra de la teoría de las descripciones definidas de Bertrand Russell, materializada en su ensayo On Referring ${ }^{15}$, constituiría el cisma en la tradición analítica de la filosofía, reconociéndose una segunda concepción en su interior. H.L.A. Hart embestiría al cientificismo de las tesis de Kelsen y de Ross, influenciado por los métodos filosóficos de J.L. Austin y P.F. Strawson, mediante una empresa orientada a describir la estructura del pensamiento jurídico a través de nuestras formas de hablar sobre el derecho. Su forma de análisis conceptual tiene como influencia a Strawson y consiste en el esclarecimiento de las relaciones que existen entre los conceptos con que pensamos un determinado fenómeno, en este caso, el derecho. Por ejemplo, el lugar del concepto de regla en la explicación del sistema jurídico da como resultado un rechazo al reduccionismo, que entiende al derecho como un sistema integrado por un solo tipo de reglas (la Gründnorm y las reglas primarias, por ejemplo). Esa explicación no hace justicia a una comprensión ordinaria del concepto de derecho, ya que el aparato conceptual con el que concebimos, imaginamos y reflexionamos sobre el derecho es más complejo de lo que plantean Kelsen y Ross, pues implica el reconocimiento de una pluralidad de tipos de reglas en el derecho. Para que se pueda decir que se está ante un sistema jurídico, es necesario entonces admitir la existencia de dos clases de reglas: primarias (de obligación) y secundarias (según Hart, de cambio, adjudicación y reconocimiento). Esta conclusión es forzada por el simple hecho de que ciertas reglas jurídicas no puedan ser satisfactoriamente explicadas como instruyendo a un oficial a que aplique una sanción (véase, por ejemplo, el caso de la banda

I4 Cf. Ross, Alf, Sobre el derecho y la justicia, traducción de Genaro Carrió, 3ra. edición, Buenos Aires: Eudeba, 1994, pp. 34-52.

I5 Cf. Strawson, P.F., "Sobre el referir", en: Ensayos lógico-lingüísticos, traducción de Alfonso García y Luis Valdés, Madrid: Tecnos, 1983, pp. II-39. 
organizada de ladrones $\left.{ }^{16}\right)$. Además de reglas que cumplen esa función, existen otras que establecen definiciones, que instruyen otro tipo de conductas a los oficiales o que otorgan facultades para realizar ciertas acciones sin que exista una sanción contemplada en el caso de incumplimiento ${ }^{17}$. De esta manera, las reflexiones de Hart suponen tomar en cuenta cómo hacemos distintas cosas con las reglas jurídicas o cómo la normatividad nos permite extendernos en la regulación de las relaciones entre las personas ${ }^{18}$. La metodología hartiana objeta las tesis normativistas y iusrealistas, en tanto que estas teorías establecen una hipótesis para medir y experimentar sobre el fenómeno jurídico.

Con Hart se produce un claro distanciamiento respecto del realismo jurídico (escandinavo), pues la limitación de los estudios de Ross y Olivecrona a la observación de conductas y hechos verificables empíricamente desatienden considerablemente el significado de los fenómenos fácticos, vale decir, la comprensión que los partícipes de lo jurídico tienen de él. La metodología empleada por Ross no considera el sentido que tiene la realidad social estudiada para quienes forman parte de ella, solo son relevantes los comportamientos y los reportes de los estados psicológicos ${ }^{19}$. La explicación de Hart, en cambio, intenta reconstruir la estructura conceptual con que se piensa al derecho, cuestión que considera la dimensión abstracta del mismo y que la tesis de Ross no toma en cuenta. En ese sentido, existe una estrecha relación entre el análisis conceptual y la adopción de un punto de vista interno al analizar el derecho. Ahora bien, ¿cómo se investiga nuestro aparato conceptual? El método escogido por Hart en The Concept of Law consiste en prestar atención a las sutilezas de nuestras formas de hablar ${ }^{20}$. Aplicando sutiles distinciones como las de J.L. Austin en varias de sus conferencias ${ }^{21}$, observa que distinguimos en nuestro lenguaje entre "verse obligado" y "tener una obligación"22; el reconocimiento de esta

16 Cf. Hart, H.L.A., The Concept of Law, pp. 44-49.

17 Cf. ibid., capítulo II.

I8 Cf. ibid., p. vii.

19 Véase Hierro, Liborio, El realismo jurídico escandinavo: una teoría empirista del derecho, Valencia: lustel, 2008, pp. 35-69, 109-192.

20 Así como el método propugnado por Austin, J.L., Cómo hacer cosas con palabras: palabras y acciones, traducción de Genaro Carrió y Eduardo Rabossi, 2da. edición, Barcelona: Paidós, 1982.

2I Cf. Austin, J.L., Ensayos filosóficos, traducción de Alfonso García, Madrid: Alianza Editorial, 1975, especial énfasis en "Un alegato en pro de las excusas", "Tres maneras de derramar tinta" y "Emisiones realizativas".

4822 Cf. Hart, H.L.A., The Concept of Law, p. 82. 
distinción permite aclarar el defecto de la aproximación rossiana, a saber, que no explica la diferencia que existe entre, por ejemplo, la situación en que nos vemos obligados a actuar de tal o cual manera (como cuando entregamos la billetera al ladrón que nos amenaza) y la situación en que tenemos la obligación de realizar cierta conducta (como pagar los impuestos).

\subsection{The Concept of Law y la iusfilosofía anglosajona}

The Concept of Law proporcionó herramientas metodológicas inéditas al debate en la teoría jurídica del siglo XX. El método propuesto por H.L.A. Hart no tenía símil en la materia, pero sí en parte algo que Wittgenstein llamó family resemblance (parecido de familia) con, por ejemplo, The Concept of Mind (1949) de Gilbert Ryle. No fue un ensayo fundante, ya que la filosofía jurídica anglosajona (analytical jurisprudence) se remonta a la denominada "escuela analítica" integrada por los trabajos de los juristas Jeremy Bentham (An Introduction to the Principles of Morals and Legislation, 1781 y Of Laws in General, 1782) y John Austin (The Province of Jurisprudence Determinated, 1832). Austin conceptuó al derecho como la satisfacción de un deseo a partir de una obediencia debida temiendo una sanción en caso de contravención ${ }^{23}$ o, en la formulación de Hart, "órdenes respaldadas por amenazas" 24 . El entendimiento imperativo del derecho, que posiciona a la coacción como algo esencial a lo jurídico, se puede ver manifestado en una forma más científica con el normativismo de Kelsen.

El propósito último de hacer una teoría pura del derecho fue la creación de un concepto de derecho exento de la influencia de cualquier otra disciplina que pudiera embarazar su idóneo análisis. No obstante lo anterior, sería la obra de Hart de 1961 la que revolucionaría la teoría jurídica de la mano de la filosofía del lenguaje (ordinario) que la cobijó, en oposición a las tesis sobre el lenguaje ideal caracterizadas por el Círculo de Viena.

La visión del derecho de Hart resulta de una aplicación de la concepción cotidianista en la tradición analítica en filosofía. Esta última rechazó la intuición

23 Cf. Austin, John, Lectures on Jurisprudence: Or the Philosophy of Positive Law, Londres: John Murray, I873, p. 220.

24 Hart, H.L.A., The Concept of Law, p. 20. 
básica de su rival, la concepción cientificista, según la cual la evaluación filosófica de la modernidad arrojaba por conclusión que el lenguaje de la ciencia experimental de la naturaleza es el tribunal ante el que corresponde dar examen al resto del lenguaje. La función principal del lenguaje, según la concepción cientificista, sería la descripción del mundo, de la cual la predicción del curso futuro de los fenómenos naturales es un caso particular que se traduce en la descripción de estados futuros del mundo. El análisis del lenguaje en términos de la lógica matemática de predicados (de más de una variable) y cuantificadores representaba el paradigma del método filosófico. La concepción cotidianista, por el contrario, sostiene que el lenguaje consiste en distintos usos de las palabras y oraciones con el fin de hacer distintas cosas. Describir es una de las cosas que el lenguaje permite, pero no es la única; también permite dar órdenes, formular peticiones, realizar preguntas, bromear, ironizar, entre otras acciones. Esos usos solo comparten un parecido de familia wittgensteniano, es decir, una afinidad entre ellos que no se reduce a un conjunto de condiciones individualmente necesarias y en conjunto suficientes ${ }^{25}$.

The Concept of Law pretende "elucidar los conceptos que constituyen la estructura del pensamiento jurídico" ${ }^{26}$. Entonces, es una reconstrucción que considera la aclaración de los conceptos jurídicos comúnmente usados. Hart, el 30 de mayo de 1953, en la conferencia dictada al momento de asumir el cargo de profesor en la Universidad de Oxford, expresó que "en el derecho, como en lo demás, podemos saber y sin embargo, no comprender"; luego añade que "las sombras que oscurecen a menudo nuestro conocimiento, no solamente cambian de intensidad, sino que son producidas por diversos obstáculos a la luz. Éstos no pueden ser eliminados todos por los mismos métodos, y mientras no determinemos el carácter preciso de nuestra perplejidad no podemos decir qué instrumentos necesitaremos" ${ }^{27}$. Además de criticar los métodos tradicionales de definición, Hart señaló que los conceptos y nociones jurídicas pueden ser elucidados por métodos adecuadamente adaptados a su carácter específico. Las perplejidades que expone el oxoniense se sitúan en

25 Cf. Wittgenstein, Ludwig, Investigaciones filosóficas, traducción de Alfonso García, México D.F.: UNAM, 1988, §§ 66-7I.

26 Hart, H.L.A., The Concept of Law, p. 80.

27 Hart, H.L.A., "Definición y teoría en la ciencia jurídica”, en: Derecho y moral. Contribuciones a su análisis, traducción de Genaro Carrió, Buenos Aires: Ediciones Depalma, 1962, p. 94. Énfasis añadido. 
las comunes interrogantes de la teoría jurídica analítica, que son campo no de aclaraciones sino de definiciones tales como ¿qué es el derecho?, iqué es un Estado?, iqué es un derecho subjetivo?, ¿qué es la posesión? Estos asuntos deben preceder a cualquier elaboración teórica, ya que el lenguaje jurídico es el que se utiliza en la práctica del derecho y, por tanto, es el lugar donde una teoría descriptiva de la realidad cumple su objetivo.

Sobre ello, Hart comparte con Kelsen la convicción de que una tarea central de la filosofía del derecho es explicar la fuerza normativa de las proposiciones jurídicas que ocurren tanto en la literatura jurídica académica, como en el discurso de jueces y abogados ${ }^{28}$. El fin de la filosofía jurídica analítica es conseguir un mejor entendimiento del derecho y de las ideas jurídicas, tanto por sí mismas como por su valor práctico. Es natural que durante toda la larga historia de estudios de filosofía jurídica se haya prestado mucha atención a los términos y a los conceptos del derecho ya que el derecho es, entre otras cosas, esencial e irreductiblemente lingüístico: las leyes se formulan y se promulgan mediante palabras, los actos y las decisiones jurídicas suponen pensamiento articulado y declaración pública. Una estructura conceptual compleja y, ciertamente, un vocabulario amplio y parcialmente especializado resultan por ello esenciales para ordenar el amplio muestrario de prácticas y actividades que constituyen un orden jurídico ${ }^{29}$.

Ahora bien, parece característico tanto del uso de los conceptos jurídicos como de otros en diferentes disciplinas y en la vida ordinaria, que tenemos que adecuar nuestra percepción para dominarlos. Y si ellos aún requieren elucidación, nos quedamos perplejos al tratar de entender nuestro propio aparato conceptual. Es posible que sepamos cómo usar esos conceptos, pero en la filosofía de Hart no podemos decir o describir con certeza cómo estos operan en la realidad; por ejemplo, es posible que sepamos cómo dibujar el mapa para llegar a un lugar, pero que al mismo tiempo no podamos explicar a otro cuál es la ruta que debe seguir para alcanzar el destino ${ }^{30}$. En ese sentido, la obra completa de Hart no pretende narrar novedades sobre

28 Cf. Hart, H.L.A., Essays in Jurisprudence and Philosophy, Oxford: Oxford University Press, 1983, p. 18.

29 Cf. MacCormick, Neil, H.L.A. Hart, Madrid: Marcial Pons, 20I0, pp. 8I-82.

30 Al respect, sugerimos ver Hart, H.L.A., "Analytical Jurisprudence in Mid-Twentieth Century: A Reply to Professor Bodenheimer", en: University of Pennsylvania Law Review, CV (1957), 
el derecho a sus lectores, sino que se dispone a decirles cosas nuevas acerca de las cosas que ya saben acerca del derecho. De ello se sigue que si uno va a contarse dentro de los pretendidos lectores de Hart, existe un cierto bagaje de conocimiento sobre el derecho que se debe tener ${ }^{31}$ (por ejemplo, que las leyes de un determinado país conforman una suerte de sistema; que los sistemas jurídicos son en todos los países, generalmente, similares en su estructura; que la existencia del derecho implica que ciertos tipos de conducta humana no son opcionales, no obstante, sí en un sentido obligatorios; que el ordenamiento jurídico de un Estado moderno está caracterizado por un cierto grado de supremacía en su territorio y, además, por la independencia de otros ordenamientos; que los sistemas jurídicos en todos los países también comprenden reglas de varias clases ${ }^{32}$ ).

The Concept of Law puede ser entendido a la vez como una obra de teoría jurídica analítica y como un ensayo de sociología descriptiva. La pretensión de que el análisis conceptual nos enseña no solo sobre las palabras sino también sobre las realidades a las que se refieren es un supuesto metodológico que Hart comparte con J.L. Austin. Ahora bien, la caracterización que Hart hace de su investigación puede parecer ambigua, pues icómo puede un análisis conceptual enseñarnos algo más que las maneras de cómo hablamos y pensamos? La pregunta es motivada por la convicción de que existe una separación entre el lenguaje y el mundo, en virtud de la cual existen dos tipos de conocimiento: por un lado, uno a priori y analítico (como el que nos entrega el análisis conceptual) y, por otro, uno a posteriori y sintético (como el que nos entrega la ciencia). Estas dos formas de conocimiento parecen en principio incompatibles, en el sentido de que los métodos que permiten obtener el primero excluyen la experiencia.

p. 97I y Hart, H.L.A., “Theory and Definition in Jurisprudence”, en: Procedings of the Aristotelian Society. Supplementary Volumes, XXIX (1955), p. 244ss.

3I Sobre los lectores de Hart, véase Duarte D'Almeida, L., J. Edwards y A. Dolcetti, "Hart's Readers", en: Reading H.L.A. Hart's The Concept of Law. Oxford: Hart Publishing, 2013, p. 2ss. 32 Por ejemplo, "(I) reglas que prohíben o hacen obligatorios ciertos tipos de conducta bajo amenaza de aplicar una pena; (II) reglas que exigen que indemnicemos a quienes hemos dañado de ciertas maneras; (III) reglas que especifican qué es lo que tenemos que hacer para otorgar testamentos y celebrar contratos u otros acuerdos que confieren derechos y crean obligaciones; (IV) tribunales que determinan cuáles son las reglas y cuándo han sido transgredidas, y que fijan el castigo a aplicar o la compensación a pagar; (V) una legislatura que hace nuevas reglas y deroga las anteriores" (Hart, H.L.A., The Concept of Law, p. 3). 
Ahora bien, es popular entre los comentaristas entender The Concept of Law como una investigación a priori ${ }^{33}$. Esto le ha merecido la crítica según la cual, por tener esa cualidad, no puede entregarnos conocimiento relevante (esto es, no trivial). Sin embargo, algunos autores, como Joseph Raz, han entendido que esa es la forma que las investigaciones acerca de la naturaleza del derecho deben tomar ${ }^{34}$. ¿Qué hay, entonces, en The Concept of Law que permita una lectura de este como una contribución a la sociología descriptiva?

Para comprender en qué medida la obra de Hart puede entenderse como una investigación sociológica, debemos recordar que la descripción desde lo que el autor llama punto de vista externo no permite entender la manera en que las reglas configuran los fenómenos sociales. Esto vale para fenómenos que van desde prácticas como la cortesía hasta instituciones como el derecho. Solo adoptando el punto de vista interno, i.e. el punto de vista de un participante comprometido con la práctica, es posible entender las acciones de los individuos que constituyen las realidades estudiadas como acciones posibles de ser justificadas por referencia a las reglas que las conforman, reglas que entregan a los agentes razones para actuar ${ }^{35}$. Solo desde el punto de vista interno es posible constatar la existencia de esas reglas, por oposición a la simple convergencia de comportamientos: mientras que una descripción desde el punto de vista externo solo señala una correlación entre, por ejemplo, la luz verde del semáforo y el movimiento de los automóviles, un análisis desde el punto de vista interno podrá entender la luz como una razón que justifica ese movimiento.

La introducción de esta metodología descriptiva requiere de la existencia de una regla de "reconocimiento", la cual se manifiesta en la práctica generalizada

33 Por ejemplo, Lacey, Nicola, A Life of H.L.A. Hart: The Nightmare and the Noble Dream, Oxford: Oxford University Press, 2004; Soper, Philip, A Theory of Law, Cambridge, Mas.: Harvard University Press, 1984; Green, Leslie, “Reconsiderando el concepto de derecho", en: Figueroa Rubio, Sebastián (ed.), Hart en la teoría del derecho contemporánea, Santiago de Chile: UDP, 2014, pp. 19-60.

34 Un ejemplo de ello es su ensayo Authority, Law, and Morality.

35 Cf. Shapiro, Scott J., "What Is the Internal Point of View?", en: Fordham Law Review, LXXV (2006), pp. II57-II70. Acerca del argumento de las razones para la acción, véase Raz, Joseph, Practical Reason and Norms, 2da edición, Princeton: Princeton University Press, 1990, pp. 15-48. 
de funcionarios y particulares al identificar normas mediante dichos criterios $^{36}$. Esta regla se mueve entre enunciados internos y externos, pues la aceptación y seguimiento de las normas de un sistema jurídico requiere de la validación de los sujetos imperados por dicho ordenamiento. Para Hart, existen dos condiciones necesarias y suficientes para la existencia de un orden jurídico: las normas de conducta válidas (según el criterio de validez último del sistema, esto es, ser generalmente obedecidas) y sus reglas de reconocimiento que especifican el pedigree (origen), los criterios de validez jurídica y sus normas de cambio y adjudicación que efectivamente deben ser aceptadas por sus funcionarios como pauta o modelo público de conducta oficial ${ }^{37}$. Con esto, Hart contesta a la pregunta "iqué son las reglas, y en qué medida el derecho es una cuestión de reglas?", una de sus tres interrogantes persistentes esbozadas al inicio de The Concept of Law.

El texto de Hart, además de incorporar una propuesta sociológica que permea al derecho, se ocupa de responder, a través del análisis conceptual, a I) ien qué se diferencia el derecho de las órdenes respaldadas por amenazas, y qué relación tiene con ellas? y 2) ien qué se diferencia la obligación jurídica de la obligación moral, y qué relación tiene con ella? Las tesis anteriores al libro de Hart (pensemos en Austin y Kelsen) referían a una clase de normas, las que imponen obligaciones (duty-imposing rules) ${ }^{38}$. Sin embargo, en el derecho también existen reglas que "definen la manera de realizar contratos, celebrar matrimonios u otorgar testamentos válidos, no exigen que las personas actúen de modos determinados, lo quieran o no. Tales normas no imponen deberes u obligaciones. En lugar de ello, acuerdan a los particulares facilidades para llevar a cabo sus deseos, al otorgarles potestades para crear, mediante ciertos procedimientos específicos y bajo ciertas condiciones, estructuras de facultades y deberes dentro del cuadro coercitivo del derecho. La potestad así conferida a los individuos para dar forma a sus relaciones jurídicas con los demás mediante contratos, testamentos, matrimonios, etc., es uno de los

36 Cf. Tamayoy Salmorán, R., "Estudio preliminar”, en: Hart, H.L.A., Post scríptum al concepto de derecho, México D.F.: UNAM, 2000, p. xxvii.

37 Cf. Hart, H.L.A., The Concept of Law, p. II3.

38 Según Kelsen, reglas genuinas o primarias que regulan supuestos de hecho, que de cumplirse imponen una sanción a quien incurrió en lo descrito por la norma. En la vereda austiniana, la fórmula de órdenes respaldadas por amenazas, simplemente, son lo único que califica como derecho/ley. 
grandes aportes del derecho a la vida social; y es una característica que queda oscurecida si se representa a todo el derecho como una cuestión de órdenes respaldadas por amenazas" 39 . Estas normas potestativas (power-conferring rules) se diferencian de las otras en el marco de nuestros modos corrientes de hablar; por ejemplo, cuando contrato, no estoy cumpliendo la norma que me faculta; cuando no contrato, no la violo ni la incumplo. Si no satisfago los requerimientos de la norma que faculta, el acto es nulo, no es válido, no producirá efectos. No obstante, pese a que el acto es nulo, no infrinjo norma alguna, por tanto no hay conducta mía que sea ilícita.

Para el caso de la segunda interrogante, la postura hartiana se inclina por una separación entre la moral y el derecho, la llamada "tesis de la separabilidad"40. Ella proviene del siguiente pasaje de The Concept of Law: "hay muchos tipos de relación entre el derecho y la moral, y no hay nada que pueda ser singularizado con provecho para ser estudiado como la relación entre ellos"4l. Hart postula que ninguna de estas relaciones se da en forma necesaria. Sí es posible que existan enlaces de carácter contingente, pues para él, en primer lugar, las estructuras sociales no deben descansar en creencias cuyo error puede demostrarse $y$, en segundo lugar, las protecciones frente al daño que la moral característicamente acuerda, a través de las acciones y omisiones que requiere, debe extenderse por lo menos a todos los hombres que puedan y quieran aceptar tales restricciones ${ }^{42}$. La necesidad de la conexión entre la moral y el derecho tiene el carácter de absoluta, cuestión que Hart no acepta. Sí, en una relativización del argumento donde ciertas cuestiones que parecen indispensables para una convivencia armónica en sociedad (v. gr. Limitación del uso de la violencia ante la vulnerabilidad humana, lograr una aproximada igualdad, normas sobre cooperación e intercambio por un altruismo limitado, reglas que regulen la distribución de los recursos escasos y la regulación de la propiedad privada ${ }^{43}$. En el plano de la validez de una norma, que la moral

39 Hart, H.L.A., The Concept of Law, p. 28.

40 Cf. Green, Leslie, "Positivism and the Inseparability of Law and Morals", en: New York University Law Review, LXXXIII, No. 4 (2008), pp. 1035-1058.

$4 \mathrm{H}$ Hart, H.L.A., The Concept of Law, p. 185.

42 Cf. ibid., p. 184.

43 Esto es parte de lo que Hart denominó "contenido mínimo de derecho natural" (cf. ibid., pp. 193-200). Un acercamiento inicial a este argumento se encuentra en Hart, H.L.A., "Positivism and the Separation of Law and Morals", en: Harvard Law Review, LXXI, No. 4 (1958), pp. 
diga que una ley es justa o injusta no afecta nunca el estatus de la misma. El positivismo jurídico no negocia con esta formulación ${ }^{44}$.

\section{§ 3. Propósitos y métodos en la filosofía jurídica analítica de los siglos XX y XXI}

\subsection{Propósitos: valoración y descripción}

¿En qué consiste la adopción del punto de vista interno? Contemporáneos de Hart como Ronald Dworkin o John Finnis sostienen que para entender el derecho "desde adentro" es necesaria una evaluación acerca del valor y los fines del derecho ${ }^{45}$. Para diferenciarse claramente de estas posiciones, Hart refina su entendimiento del punto de vista interno en el Postscript a The Concept of Law, texto póstumo con el que intentó responder a sus críticos ${ }^{46}$,

593-629 y en Hart, H.L.A., “Are there any Natural Rights?”, en: The Philosophical Review, LXIV (1955), pp. |75-191.

44 Mayor referencia en nuestro H.L.A. Hart y las sirenas cientificistas: una genealogía de la tradición analítica de la filosofía del derecho de los siglos XX $X X X I$, tesis de licenciatura en Derecho, Santiago de Chile, Universidad de Chile, Facultad de Derecho, 2015.

45 Cf. Dworkin, Ronald, Law's Empire, Oxford: Hart Publishing, 1998, capítulo I; Finnis, John, Ley natural y derechos naturales, traducción de Cristóbal Orrego, Buenos Aires: Abeledo-Perrot, 2000, capítulo I.

46 Con posterioridad al fallecimiento de Hart en 1992, existiría una decisión editorial de Oxford University Press de lanzar una segunda edición de The Concept of Law, a la que sus editores, Penelope A. Bulloch y Joseph Raz, añadirían el Postscript en la parte final del libro. Ellos declararon que: "Por muchos años, Hart tuvo en mente añadir un capítulo a The Concept of Law (...) él quiso responder a muchas de las discusiones del libro, defendiendo su posición en contra de aquellos que lo malinterpretaron, refutando la crítica infundada y -con igual importancia en sus ojos- concediendo la fuerza de la crítica justificada y sugiriendo formas de ajustar las doctrinas del libro para armonizar dichos puntos. Ese nuevo capítulo, primariamente pensado como prefacio, pero finalmente como un postscript, estaba inconcluso al tiempo de su muerte debido solo en parte a su meticuloso perfeccionismo. También se dio a que las dudas persistentes sobre el destino del proyecto y una nada tranquila incertidumbre si él hacía justicia al vigor y la perspicacia de las tesis del libro, como originalmente se concibieron. Sin embargo, y con varias interrupciones, él insistió con su trabajo sobre el postscript y al tiempo de su muerte, la primera de las dos pretendidas secciones estuvo casi completa". Sin perjuicio de lo anterior y con el permiso de la viuda de Hart, los editores revisarían el manuscrito y convendrían en que este estaba en una versión final. En la tarea investigativa, también encontrarían notas manuales pretendidas para la segunda sección, que estaban muy fragmentadas para ser publicadas. La versión del Postscript que se publicó había sido re-escrita, revisada e incluso re-revisada por Hart. La misión por publicar un Postscript digno del calibre académico de Hart fue una tarea ardua para los editores, donde compararon versiones alternativas del texto. Según ellos, el que efectivamente se colocó en el libro incluía todas las enmiendas que no fueron descartadas por Hart y que aparecían en la versión del último compendio que estaba revisando. En los cometidos 
observando que la adopción de este punto de vista no exige un compromiso con la práctica.

Dworkin expresó que toda teorización acerca de una práctica humana (entre las que incluye especialmente el derecho) refleja los valores de quien la propone. Así, por ejemplo, el positivismo hartiano se esforzaría por excluir los estándares morales como parte del derecho (a través de la regla de reconocimiento ${ }^{47}$ ) porque valora (en sentido moral) que el derecho y la moral no se vuelvan indistinguibles entre sí. Hart, en el Postscript, rechaza la idea de que no sea posible hacer filosofía del derecho sin que medie una evaluación de carácter moral. Al mismo tiempo, reconoce que es necesaria una evaluación, pero ella consiste solo en seleccionar qué parte de la realidad social se analizará. Esta evaluación no es moral ${ }^{48}$. La idea de lo descriptivo no caracteriza al derecho, pero sí al hecho de hacer una teoría, al ejercicio intelectivo de teorizar en torno a un aspecto puntual del caso.

"Análisis" se refiere a descomponer algo en sus partes constituyentes. He ahí la lucha entre el descriptivismo y el imperio, esto es, el debate Hart-Dworkin ${ }^{49}$. The Concept of Law solo provee las herramientas para ir hacia la sociología descriptiva, según la cual un individuo puede distinguir entre situaciones, por

finales (revisión de citas, referencias, frases dudosas e incompletas), los editores recibieron la ayuda de Timothy Endicott. Luego, finalizan la nota editorial expresando que "No hay duda en nuestras mentes que si Hart, teniendo la oportunidad, él tendría un texto más pulcroy mejorado antes de su publicación. Pero creemos que el postscript publicado contiene sus consideradas respuestas a muchos de los argumentos de Dworkin" (Bulloch, P.A. y Joseph Raz, "Editors' Note", En: Hart, H.L.A., The Concept of Law. p. viii). De todas maneras, para ser un trabajo póstumo, el Postscript superó las expectativas de sus editores y de los críticos, puesto que sus sucesores adoptaron como brújula la proyección de las tesis de Hart de este texto.

47 Los esfuerzos teóricos más relevantes por negar que reglas morales puedan ser parte del derecho fueron llevados a cabo por Raz y no por Hart. Esta posición (llamada con posterioridad positivismo duro o excluyente) fue atribuida por Dworkin a Hart, aunque nada en The Concept of Law se pronunciaba en ese sentido. Más aun, Hart, en el Postscript, abraza explícitamente el positivismo blando (según el cual los estándares morales pueden formar parte del derecho, pero no de manera necesaria). Además del Postscript, véase Raz, Joseph, "Autoridad, derechoy moral”; Waldron, Jeremy, "Positivismo normativo (o ético)", en: Orellana Benado, M.E. (comp.), Causas perdidas. Ensayos de filosofía jurídica, política y moral, Santiago de Chile: Catalonia, 20I0, pp. $125-144$.

48 Sobre la importancia de distinguir valores epistémicos, véase Putnam, Hilary, El desplome de la dicotomía hecho-valor y otros ensayos, Barcelona: Paidós, 200I, p. 44.

49 Nos remitimos a la conceptualización de Shapiro, Scott J., "The 'Hart-Dworkin' Debate: A Short Guide for the Perplexed”, en: Ripstein, A. (ed.), Ronald Dworkin, Cambridge: Cambridge University Press, 2007, pp. 22-55. 
ejemplo decir por qué las personas habitualmente siguen a otras, por qué aceptan una determinada orden, por qué hay razones para la acción, por qué opera de una forma definida el sistema, entre otras ${ }^{50}$. Esta cuestión ha sido llamada, por autores como Brian Bix, como un giro hermenéutico en la filosofía del derecho ${ }^{51}$.

\subsection{Métodos: análisis conceptual y naturalismo jurídico}

A diferencia de la obra de Hart, la de Raz se presenta como una empresa abiertamente conceptual, pues él afirma que la filosofía del derecho debe proceder investigando nuestro concepto de derecho y su relación con otros conceptos. De este modo, Raz parte de un análisis del concepto de autoridad y de él deriva conclusiones acerca de la naturaleza del derecho. En particular, respecto del debate entre positivismo incluyente o blando (inclusive/soft) y excluyente o duro (exclusive/hard), se pronuncia a favor del último. Raz dice que hay veces en que el derecho reclama autoridad (verdad conceptual) $y$, más aun, sostiene que el tener autoridad legítima muestra una relación entre verdad y sujeto. Por lo mismo, su concepto de derecho implica reclamar autoridad: el derecho pretende dar razones para actuar y los comportamientos que el derecho impone no son opcionales, sino que se sustentan solamente en la amenaza de sanción. Sobre la autoridad, él establece tres tesis para dilucidar este concepto ${ }^{52}$.

50 Cf. Sugarman, David y H.L.A. Hart, "Hart Interviewed: H.L.A. Hart in Conversation with David Sugarman”, en: Journal of Law and Society, XXXII, No. 2. (2005), pp. 289-292; véase también MacCormick, Neil, op. cit., p. 8 I.

5I Cf. Bix, Brian, Teoría del derecho: ambición y límites, varios traductores, Madrid: Marcial Pons, 2006, p. 183ss.

52 (i) Dependencia: relación entre las razones que la autoridad da a los sujetos y las razones que los sujetos tienen con independencia de la autoridad. Las razones de autoridad se aplican a los sujetos y estos las sopesan para realizar actos. En la sociedad son muchos [ia qué se refiere con "muchos": a los sujetos o a las razones?] por lo que hay que conciliar las razones para coordinar sus decisiones. Así, la autoridad media entre los sujetos y las razones que les aplican. Además, hay sujetos que no poseen la capacidad de razonar. También, la autoridad determina las razones $y$, en función de ellas, emite directivas que reemplazan las razones de los sujetos, pero que a la vez las utiliza de base para evaluar y fijar las de más peso. La consecuencia es que las directivas de la autoridad dependen de las razones que tendrían inicialmente los individuos. (ii) Justificación normal: ella se homologa a lo que es la legitimidad. Según Raz, esto ocurre cuando los sujetos actúan normalmente de acuerdo a las mejores razones que se les aplican siguiendo las directivas de la autoridad. (iii) Exclusividad: se refiere a la forma en que debieran operar las razones autoritativas en el razonamiento de los individuos. Ellas deberían operar como razones 
La preferencia de Raz por el método de análisis conceptual y el bombeo de intuiciones motivó la crítica de Brian Leiter, quien declara que con el desplome de la dicotomía analítico/sintético cae también la confiabilidad del análisis conceptual ${ }^{53}$. Es opinión de Leiter, en línea con el naturalismo de W.V. Quine, que el análisis conceptual y la investigación empírica deberían trabajar en conjunto. Sin embargo, las críticas reflexiones de Leiter sobre el análisis conceptual parecen apresuradas e innecesarias para sus propósitos. En primer lugar, porque no es claro cómo la crítica de Quine a la distinción analítico/sintético trae consecuencias para los análisis conceptuales más allá de casos sencillos como ocurre con las definiciones de, por ejemplo, "azul" o "soltero" ${ }^{4}$. Hart rechazó explícitamente la pretensión de definir el concepto de derecho, mientras que los análisis de Raz no pretenden ser una definición del concepto de autoridad ${ }^{55}$. Además, si lo que Leiter busca es integrar los conocimientos obtenidos por medios experimentales con análisis conceptuales, sus críticas estarían fuera de lugar, porque el análisis conceptual nunca excluyó tal posibilidad ${ }^{56}$. Con ello, se concluye que el giro naturalista en la filosofía del derecho es el paradigma de este tiempo. Si parecen separarse, esto se debe probablemente a prejuicios empiristas acerca de los tipos de conocimiento que existen. Según J.L. Austin, el lenguaje (y el análisis conceptual), si bien no tiene(n) la última palabra respecto a cómo sea el mundo, al menos tiene(n) la primera. De ahí nuestra insistencia en la pregunta respecto de si hay o no un concepto analítico de derecho.

de segundo orden, lo que quiere decir que excluyen razones de primer orden; deberían hacer que los individuos no recurran a sus primeras razones. Un sujeto que reconoce una autoridad la sigue, pero no evalúa la conveniencia de aplicar sus razones al momento de actuar (cf. Raz, Joseph, "Autoridad, derecho y moral", en: La ética en el ámbito de lo público, Barcelona: Gedisa, 200I, pp. 227-257).

53 Una reflexión naturalizada del derecho implica una lectura de Naturalizing Jurisprudence de Brian Leiter, obra que pretende dar cuenta de la facticidad que puede ser medida a través de la ciencia, más que ser una piedra angular para elaborar una teoría del derecho. Sin embargo, en este autor, el juego con una teoría del derecho es posible, pues las justificaciones permiten descripción y explicación, pero no cuestiones ontológicas que sí las necesitaría una postura que pretendiera intentar indagar tras la idea del concepto o la naturaleza del fenómeno jurídico. Para mayor referencia, véase nuestro artículo "El naturalismo jurídico como teoría del derecho: red filosófica y conceptual de un cientificismo revisitado", en: Derecho y Humanidades, XXII (20I3), pp. I8I-224.

54 Cf. Quine, W.V., Desde un punto de vista lógico, Barcelona: Paidós, 2002, pp. 6I-9I.

55 Véase Raz, Joseph, Between Authority and Interpretation, Oxford: Oxford University Press, 20I0, capítulos III y IV.

56 Sobre el análisis de Leiter, véase Leiter, Brian, Naturalismo y teoría del derecho, traducción de G.B. Ratti, Madrid: Marcial Pons, 20I2, capítulo VI y su apéndice. 


\section{$\S 4$. ¿Un concepto analítico?}

La teoría jurídica analítica busca esclarecer la estructura general del pensamiento jurídico y no, como bien dice Hart, "de la crítica del derecho o política jurídica" ${ }^{57}$. Se trata de investigar cómo se reflexiona en torno al fenómeno normativo y no de una especie de sistema en particular. Por lo mismo, Hart se refiere a su teoría como eminentemente general y no circunscrita a un objeto en particular. Después de 1961, la teoría analítica del derecho y los herederos de Hart querían descubrir o explicar la naturaleza del derecho ${ }^{58}$; siguiendo con los parámetros dejados por la obra cumbre de Hart, se potenció el interés por ir hacia esa idea transversal que prima facie subyace a cualquier concepto del derecho.

“¿Qué es el derecho?” fue una pregunta que suscitó un enorme debate posterior, con miras a acordar lo que realmente es una aproximación equivocada al concepto de derecho, ya que este tiene un carácter equívoco. Dworkin reconoció la existencia de desacuerdos acerca de lo que es el derecho, lo que no necesariamente implica dicotomizar la argumentación respecto de lo qué es el concepto y lo qué no es ${ }^{59}$; por tanto, la idea de que de un particular se deduzca un universal es a priori una cuestión que requiere de un ejercicio inductivo que es difícil que surja de un análisis conceptual. Raz parte de la misma base, pero estima que es la naturaleza del derecho la que da los conceptos a partir de la idea de las propiedades esenciales del mismo, aquellas que hacen que cualquier cosa sea derecho en términos intemporales.

El hecho de otorgar un concepto, esto es, una "noción general de un objeto”60, puede admitir los siguientes objetivos: (i) buscar y explicar los usos lingüísticos; (ii) descubrir el significado de un concepto que subyace de nuestras prácticas institucionales; (iii) formular un criterio o estándar normativo, el cual debe satisfacer la noción para que pueda ser aplicada ${ }^{61}$. Detrás de cualquiera de estos

57 De Páramo, Juan Ramón, H.L.A. Hart y la teoría analítica del derecho, Madrid: Centro de Estudios Constitucionales, 1984, p. 19.

58 Cf. Etcheberry, Juan B., Objetividad y determinación del derecho. Un diálogo con los herederos de Hart, Granada: Comares, 2009, p. 14.

59 Cf. Dworkin, Ronald, Law's Empire, pp. 3-4.

60 Fowler H.W. y F.G. Fowler, The Concise Oxford Dictionary of Current English, editado por Angus Stevenson y Maurice Waite, 12a edición, Oxford: Oxford University Press, 201I, p. 209. 
parámetros, se oculta la forma en que concibamos el efecto "sistematizador" que pretende esa noción general. Es más, la empresa hartiana ostenta las ideas de (i) y (ii). No así Dworkin, que puede situarse en (iii), aunque si se abstrae la teoría de la adjudicación del oxoniense, sería posible aplicar el criterio que le falta. Empero, a Raz le es indiferente este esquema planteado por Bix.

Coincidimos con Esteban Pereira Fredes cuando dice que en la concepción de Hart no hay claridad sobre si el objetivo de su obra es ir por el concepto de derecho o solo proporcionar un concepto de derecho. Lo primero sería reconocer que la conceptualización en torno a lo jurídico es un esfuerzo teórico que busca otorgar una noción general con pretensiones y caracteres de universalidad y necesidad. No así lo segundo, pues implicaría la existencia de más conceptos de derecho, lo que reconduciría la fijación en una cuestión meramente contingente ${ }^{62}$. Aunque el mismo Hart podría afirmar que su trabajo está diseñado para ofrecer elementos de el concepto de derecho ${ }^{63}$, quizás la formulación de este pueda ser un paso más cerca de sus aspiraciones de alcanzar el fin de la filosofía del derecho, vale decir, un entendimiento general y sistemático de su objeto de estudio ${ }^{64}$. Y si se intenta conciliar con esta interpretación de la obra de Hart, iel ofrecer elementos no viene a ser lo mismo que la idea raziana de las propiedades esenciales del derecho, esto es, su naturaleza?

La discusión se inclina indefectiblemente hacia la metodología y los propósitos de la teoría del derecho; Hart, en una vereda, enfatiza que el contenido valorativo es prescindible para entregar un concepto ${ }^{65}$; Julie Dickson, quien se suma a la controversia, defiende la evaluación e intenta dilucidar qué es lo que requiere una teoría del derecho para ser exitosa; y la misma reflexión, pero en torno a la posibilidad de verla como empresa epistémica sustentable, subyace en las tesis de Raz y en la de Pereira Fredes.

62 Cf. Pereira Fredes, Esteban, "La teoría del derecho como posibilidad. Reflexiones sobre la naturaleza y el concepto de derecho", en: Revista de Estudios de la Justicia, XIV (20I2), pp. 86-87.

63 Véanse las últimas páginas de Sugarman, David y H.L.A. Hart, op. cit.

64 Cf. Dickson, Julie, Evaluación en la teoría del derecho, traducción de Juan Vega, México D.F.: UNAM, 2006, p. 21.

65 Cf. Orrego Sánchez, Cristóbal, H.L.A. Hart. Abogado del positivismo jurídico, Pamplona, EUNSA, 1997, p. 114. 
La idea de jugar con los conceptos implica dos cosas adicionales: cómo se concibe al mundo y qué ocurre con la significación que entregan las palabras por medio de las cuales son exteriorizados. A esto se suma, además, la naturaleza de las cosas a las que se aplican. Raz, a propósito del estudio de los conceptos, supone dos cosas: (a) que se pueden explicar lo que son, explicando qué es tenerlos y comprenderlos; y (b) que difieren entre sí por la información requerida para tenerlos y entenderlos, y por las destrezas y habilidades involucradas en su posesión ${ }^{66}$. Ello solamente está imbricado con un ejercicio reflexivo; ahora bien, Raz piensa en la noción de esencia de Aristóteles, es decir, aquello que una cosa necesita para ser tal, lo que le da identidad, sin la cual pasa a ser otra cosa. Agrega el israelí, "el conocimiento completo del concepto (...) consiste en el conocimiento y comprensión de todas las propiedades esenciales de...."67. Las propiedades esenciales son patrones generales que debe contener toda formulación para referir un objeto. El análisis conceptual queda constreñido a la unidad en sí y no a cómo es posible elucubrarla. Por tanto, los conceptos requieren de condiciones mínimas para su dominio y también para su posesión. Con ello, el individuo se apropia del relato y lo hace propio, esto en el caso de que desee dar su concepto de derecho. Lo anterior es válido si se ciñe al estricto respeto de los patrones.

Sobre el concepto de derecho, Hartyerra en la pretensión general de su estudio. La orientación a un sistema y una realidad determinada, el sistema anglosajón, es patente. Esta perspectiva no es más que una verdad contingente. Raz lo reafirma cuando explica que obedece a una lógica contextual que se sitúa en un tiempo y espacio determinado, puesto que da cuenta de dos aspectos estructurales como lo cultural y lo histórico ${ }^{68}$. Ello quiere decir explícitamente que puede existir más de un concepto de derecho y que quizás lo obrado por Hart en 1961 no es más que otro intento por definir al fenómeno jurídico.

La controversia parece acotarse a la dicotomía entre concepto y naturaleza del derecho, lo que se conjuga en el éxito de la actividad epistémica de la filosofía jurídica ${ }^{69}$, ya que puede permitir un mejor entendimiento de las sociedades a

66 Cf. Raz, Joseph, “¿Puede haber una teoría del derecho?”, en, Raz, Joseph et al., Una discusión sobre la teoría del derecho, traducción de Rodrigo Sánchez, Madrid: Marcial Pons, 2007, p. 5 I.

67 lbid., p. 52.

68 Cf. Raz, Joseph, Between Authority and Interpretation, p. 85. 
propósito de lo que es el derecho, su funcionalidad y la pregunta por su existencia. Si se sigue a Raz, el camino es por la naturaleza del derecho, ya que la idea de elementos sine qua non de cómo entenderlo subyace al entendimiento mismo. Raz establece que los conceptos tienen cuatro partes, a saber: (I) los rasgos esenciales de la cosa de la cual es un concepto, (2) la explicación de la comprensión involucrada en el completo dominio de un concepto, (3) la explicación de las condiciones para la posesión mínima de un concepto y (4) las capacidades requeridas para la posesión mínima de un concepto ${ }^{70}$.

Al crear un concepto se involucran las cualidades que este debe tener. Raz identifica esto como la naturaleza de ese objeto, o sea, lo que se debe estudiar. En el derecho ocurre que las propiedades esenciales se definen como características universales del derecho que "deben ser encontradas en (él) dondequiera y cuando quiera que exista" "ll (la idea de la intemporalidad afirmada anteriormente). Esto es importante porque cabe que en la sociedad las personas comiencen indistintamente a realizar la labor hartiana (que no distingue claramente entre el o un concepto de derecho), lo que derivaría en muchos conceptos de derecho $y$, nuevamente, el campo argumentativo se dicotomizaría y se llegaría, por un lado, con los que son conceptos y, por el otro, con los que no lo son, o peor aún, una triple distinción de falencias en torno a ello: comprensión incompleta, posibilidad de comisión de errores y, de lleno, errores en identidad(es) ${ }^{72}$. El afán por ofrecer una solución como la de Hart queda, entonces, reducido a esta idea. Para Raz, la naturaleza del derecho parece ser más relevante que su concepto, puesto que la reflexión sobre el derecho podría resultar una cuestión epistémica fructífera y llena de premisas que pueden otorgar respuestas ( $y$ certezas, si se quiere). Comprender esto implica colocar límites al conocimiento de lo que es el derecho, lo que simboliza, $y$, de alguna manera, fijar el canon de identidad filosófica que posee en sí mismo.

En el fondo, el ir por la universalidad de la naturaleza del derecho entrega un resguardo que la vaguedad del lenguaje ordinario no otorga. Es más, existen muchas acepciones de la palabra "derecho", tanto en el español como en otro

70 Raz, Joseph, “iPuede haber una teoría del derecho?”, p. 53.

71 Ibid., p. 57.

72 Cf. ibid., p. 56. 
idioma; incluso hay lenguas foráneas, como el inglés con el caso de law y right, que tienen dos palabras para decir "derecho" en dos sentidos diferentes ${ }^{73}$. Por lo tanto, la pretensión de un lenguaje ideal se pierde y el hecho de que individuos que estén sujetos a esas condiciones elaboren unidades intelectuales, sin tener un cortafuegos que permita distinguir entre qué es derecho (semánticamente) y que no lo es, ocasiona un maniqueísmo inevitable. La naturaleza del derecho, entonces, viene a ser la idea de un "contenido mínimo" de el concepto y evidentemente de un concepto. Sin embargo, ies necesario optar por alguno? Esta parece la incansable pregunta por un concepto analítico de derecho.

\section{$\S 5$. Conclusiones}

La filosofía jurídica analítica solo queda afianzada como tal con la publicación de The Concept of Law en 196I. Hacia adelante, la configuración de cualquier debate en la materia estará constreñida por los marcos del texto de Hart o por lecturas en torno al mismo. La vastedad del pensamiento de Hart se advierte en The Concept of Law como: "El tema principal de este libro es que son tantos los actos distintivos del derecho y tantas las ideas constitutivas de la estructura del pensamiento jurídico que requieren para su elucidación la referencia a uno o ambos de estos tipos de reglas, que su unión puede ser considerada en justicia como la 'esencia' del derecho, aunque los dos tipos de reglas no siempre aparezcan juntas dondequiera que se use correctamente la palabra 'derecho'"74.

Hoy parece no existir discusión sin relacionarla con The Concept of Law y, aunque se discuta con los principales textos del enfoque continental de la filosofía jurídica analítica, con el realismo norteamericano y con el neoconstitucionalismo, el parangón con el texto de 1961 es imprescindible. Cualquier genealogía de la tradición analítica de la filosofía del derecho o de la metafilosofía jurídica del siglo $\mathrm{XX}$ implica tener como punto de referencia al libro de Hart. Parafraseando a una de sus influencias, la obra de Hart no es la última palabra de la filosofía analítica del derecho, sino que podría ser la primera.

73 Un argumento a favor de la vaguedad (jurídica) se encuentra en Endicott, T.A.O., Vagueness in Law, Oxford: Oxford University Press, 2000, primeros dos capítulos. 
Confeccionado el mapa de la filosofía jurídica analítica del siglo $\mathrm{XX}$, es posible preguntarse por un rasgo que metafilosóficamente la caracterice. Esto es, si existe un concepto analítico de derecho. La calidad de analítico, en filosofía pura, tiene unos límites muy difuminados. Pero, en definitiva, la delimitación y la búsqueda del concepto analítico son fructíferas para los siguientes fines:

(i) Aumentar la discusión historiográfica sobre la ontología del derecho al interior de la tradición analítica de la filosofía jurídica.

(ii) Traslapar métodos y propósitos por el tamiz del naturalismo jurídico solo podría determinar si la tesis de Leiter es cierta o no y, con eso, forzar nuevas disputas.

(iii) Alcanzar la pregunta sobre la posibilidad de una metateoría del derecho y cómo esta se articula. Ella se descompone en una arista en la discusión erudita en teoría jurídica analítica, si se piensa en una genealogía de una tradición de pensamiento que ha volcado los problemas de la filosofía a cuestiones del lenguaje.

(iv) Interrogar la aplicación de la herramienta metafilosófica de tradiciones y concepciones de M.E. Orellana Benado, en tanto autores de inspiración tomista en el seno de la filosofía jurídica como John Finnis, Robert P. George, Mark C. Murphy, Cristóbal Orrego Sánchez, entre otros, que intentan acoplarse de forma política a la tradición analítica ${ }^{75}$.

(v) Aportar insumos metafilosóficos destinados a ordenar la historia de la filosofía analítica del derecho de los siglos XX y XXI.

(vi) Seguir releyendo y desentrañando The Concept of Law, a más de medio siglo de su primera publicación, cada vez adjudicándole una mayor o menor extensión de sentido.

75 Para este punto, se puede profundizar la lectura con Orrego Sánchez, Cristóbal, Analítica del derecho justo, México D.F.: UNAM, 2006. 